\title{
Non-cross-linked collagen type I/III materials enhance cell proliferation: in vitro and in vivo evidence
}

Ines WILLERSHAUSEN ${ }^{1}$, Mike BARBECK ${ }^{2}$, Nicole BOEHM ${ }^{3}$, Robert SADER ${ }^{3}$, Brita WILLERSHAUSEN ${ }^{1}$, Charles James KIRKPATRICK ${ }^{2}$, Shahram GHANAATI ${ }^{2,3}$

\footnotetext{
1- Department of Operative Dentistry, University Medical Center of the Johannes Gutenberg University, Mainz, Germany.

2- Institute of Pathology, REPAIR-Lab, University Medical Center of the Johannes Gutenberg University, Mainz, Germany.

3- Department of Oral, Cranio-Maxillofacial and Facial Plastic Surgery, Medical Center of the Goethe University Frankfurt, Frankfurt am Main, Germany.
}

Corresponding address: Dr. Shahram Ghanaati - Department of Oral, Cranio-Maxillofacial and Facial Plastic Surgery, Medical Center of the Goethe University, Theodor-Stern-Kai 7 60596, Frankfurt/Main - Germany - Phone: +49-6131-17-4003 - Fax: +49-6131-17-474003 - e-mail: ghanaati@uni-mainz.de

Submitted: May 8, 2013 - Modification: October 15, 2013 - Accepted: October 16, 2013

\section{ABSTRACT}

$\mathrm{O}$ bjective: To analyze Mucograft ${ }^{\circledR}(\mathrm{MG})$, a recently introduced collagen matrix, in vitro and in vivo, and compare it with BioGide ${ }^{\circledR}$ (BG), a well-established collagen membrane, as control. Material and Methods: A detailed analysis of the materials surface and ultra-structure was performed. Cellular growth patterns and proliferation rates of human fibroblasts on MG and BG were analyzed in vitro. In addition, the early tissue reaction of CD-1 mouse to these materials was analyzed by means of histological and histomorphometrical analysis. Results: MG showed a three-fold higher thickness both in dry and wet conditions, when compared to BG. The spongy surface of BG significantly differed from that of MG. Cells showed a characteristic proliferation pattern on the different materials in vitro. Fibroblasts tended to proliferate on the compact layers of both collagens, with the highest values on the compact side of BG. In vivo, at day three both materials demonstrated good tissue integration, with a mononuclear cell sheet of fibroblasts on all surfaces, however, without penetrating into the materials. Conclusions: The findings of this study showed that MG and BG facilitate cell proliferation on both of their surfaces in vitro. In vivo, these two materials induce a comparable early tissue reaction, while serving as cell occlusive barriers.

Keywords: Collagen type I. Collagen type III. Guided tissue regeneration. Bone regeneration.

\section{INTRODUCTION}

Collagen is the most abundant protein in the human body, amounting to approximately one third of the whole body weight. It consists of a highly conserved molecule, can be found ubiquitously and is a major component of human connective tissue. As an integral part of guided tissue and guided bone regeneration (GTR and GBR, respectively) procedures within periodontal, mucogingival and maxillofacial surgery, collagen membranes have become widely established over the last 30 years $2,18,19,26,27$. Their high popularity for multiple surgery indications has many reasons. Non-resorbable membranes such as expanded polytetrafluoroethylene (ePTFE) require a second operation for their retrieval ${ }^{6,12}$, while resorbable membranes show a very fast biodegradation ${ }^{2,9,13}$. To adapt the lifetime of a GBR-/GTR-membrane, which is fundamental to fulfill the goal of optimal tissue regeneration, various types of collagenbased membranes have been introduced into the market, with increasing significance attributed to a new generation of native collagens ${ }^{16,25}$. Regarding their tissue reactions, controversial opinions on the tissue integration and vascularization of collagen membranes exist in the literature. In an in vivo study ${ }^{23}$, collagen membranes with different specifications regarding their vascularization and biodegradation were investigated in a subcutaneous 
implantation model in Wistar rats. It was shown that BioGide (BG), a non-cross-linked, porcine-derived type I and III collagen membrane, promoted a rapid vascularization and experienced a relatively fast breakdown. Already two weeks after implantation of this xenograft, a nearly complete vascularization was reported with blood vessels reaching almost every part of the membrane. Contradictory results, on investigating the very same membrane in a similar study design, have been reported?. When investigating $B G$ in a subcutaneous implantation model in CD-1 mice, neither a rapid vascularization nor an early breakdown of the membranes was observed. The membrane remained within the connective tissue as a stable barrier up to 30 days and was integrated rather than biodegraded. Only mild vascularization was observed, mainly at the interfaces of the membrane, which again supports the hypothesis that it is integrated within its implantation bed, adapting to the vascularization of the latter. The observed in vivo data on BG were similar to those observed in an in vivo study ${ }^{8}$ about Mucograft (MG), another non-cross-linked type I and III collagen-based material, which is considered to serve as a matrix scaffold for soft tissue regeneration. The aim of the present study was to analyze two collagen-based materials MG and $\mathrm{BG}$ in vitro and in vivo. We hypothesize that they contribute to similar early proliferation rates of human gingival fibroblasts and induce a comparable cellular tissue response after implantation.

\section{MATERIAL AND METHODS}

\section{Biomaterials}

Mucograft ${ }^{\circledR}$ (Geistlich Pharma AG, Wolhusen, Switzerland) is a pure collagen type I and III matrix of porcine origin without further cross-linking. One part of the matrix is a thin, smooth and low-porosity compact layer $(\mathrm{CL})$ while the other part is a thicker porous and three-dimensional spongy layer (SL). While the CL has elastic properties and is supposed to permit suturing to the host mucosal margins, the $\mathrm{SL}$ should enable tissue adherence and mediate wound healing and cell integration.

BioGide $^{\circledR}$ (Geistlich Pharma AG, Wolhusen, Switzerland) is a pure collagen type I and III membrane. The collagen membrane is processed into a bilayered structure; one side of the structure is compact and smooth, constituting a low-porosity compact layer $(\mathrm{CL})$, whereas the other side is a more porous, three-dimensional spongy layer (SL).

\section{Thickness measurements of the collagen materials}

Thickness measurements of the collagen materials were conducted both in dry conditions and after humidification by $0.9 \%$ sodium chloride for 1 minute, using an Eclipse 80i histological microscope (Nikon, Tokyo, Japan) and the "Annotations and Measurements"-tool of the NIS-Elements 4.0 software (Nikon, Tokyo, Japan).

\section{In vitro study}

Human gingival fibroblasts were isolated from gingival tissue biopsies taken at the Department of Oral, Cranio-Maxillofacial and Facial Plastic Surgery (Medical Center of the Goethe University, Frankfurt, Germany). These cells were cultured in Dulbecco's Modified Eagle Medium (Invitrogen, Carlsbad, CA, USA) containing $1 \%$ penicillin/streptomycin (Invitrogen, Carlsbad, CA, USA) and $10 \%$ fetal bovine serum (PAA, Pasching, Austria) at $37^{\circ} \mathrm{C}$. Cells from the $4^{\text {th }}$ to the $6^{\text {th }}$ passage were used for the WST-1 test and the fluorescence staining.

\section{Specimen preparation}

To investigate the capacity of BG and MG to induce cellular proliferation of human gingival fibroblasts, circles of $0.7 \mathrm{~cm}$ in diameter of each membrane were obtained under sterile conditions with the help of a hole-punch.

WST-1 Test (Water Soluble Tetrazolium-1)

The specimens previously prepared from BG and MG were placed into 96 multiwell plates (Nunc A/S, Roskilde, Denmark) and incubated with $200 \mu \mathrm{l}$ of cell suspension, which equated to 10,000 cells per $\mathrm{ml}$ ( $\mathrm{n}=6$ for each material and test condition). Cells without membranes served as control $(n=6)$. To assess the influence of the two different sides of the collagen membrane and matrix on the vitality and proliferation of human fibroblasts, 10 $\mu \mathrm{l}$ per well of the cell proliferation reagent WST-1 (Roche, Grenzach-Wyhlen, Germany) was added and incubated for $48 \mathrm{~h}$ at $37^{\circ} \mathrm{C}$ and $5 \% \mathrm{CO}_{2}$. The formazan dye is subsequently measured using a scanning spectrophotometer (Infinite M200, Tecan, Grödig, Austria) at a wavelength of $480 \mathrm{~nm}$.

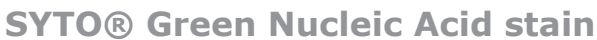

The SYTO ${ }^{\circledR}$ Green Nucleic Stain-Kit (Invitrogen, Carlsbad, CA, USA) was used to visualize the cells grown on the surfaces of the materials and to investigate their distribution/growth patterns. Briefly, the cells on the membranes were incubated with $0.5 \mathrm{mM} \mathrm{SYTO}{ }^{\circledR} 11$ at $37^{\circ} \mathrm{C}$ for $15 \mathrm{~min}$, washed with PBS, and the stained cells were then viewed in an inverted microscope at wave lengths of $450 / 520$ $\mathrm{nm}$ (Axiovert 40C, Carl Zeiss, Jena, Germany).

\section{In vivo study}

The present in vivo study for evaluation of the short-time tissue reaction to collagen-based materials was conducted after the positive consent of the Committee on the Use of Live 
Animals in Teaching and Research of the State of Rhineland-Palatinate, Germany. A total of 12 female 5-week-old CD-1 mice were purchased from Charles River Laboratories (Sulzfeld, Germany). Random distribution of the mice into two groups was performed. Consequently, the collagen-based materials were implanted into the subcutaneous tissue of the subscapular back region following an established operation model ${ }^{8}$. The animals in the first group were implanted with the MG matrix. The animals in the second group were implanted with the BG membrane as controls.

\section{Tissue preparation for animal tissue histology}

Processing and staining were performed according to previously published data ${ }^{8}$. Briefly, histochemical and immunochemical methods that are suitable for the detection of the collagen materials as well as for the evaluation of the tissue reactions were applied. All animals were sacrificed at day 3 after implantation to detect early stages of inflammatory tissue reactions. After formalin fixation, the tissue explants were cut into three identical segments that were embedded in paraffin. For the histochemical, immunohistochemical and histomorphometric analyses, nine consecutive slices from the central segment were deparaffinized, rehydrated, stained and analyzed. In addition to basic hematoxylin \& eosin stainings with one of the sections, three sections were histochemically dyed with Masson Goldner staining, Movat's Pentachrome staining and Sirius staining.

\section{Histomorphometry of in vivo thickness and cell penetration}

Total scans, i.e. digitized large images assembled from up to 120 images of the region of interest that contained the biomaterial and the peri-implant tissue at $100 x$ magnification and a resolution of $2500 \times 1200$ pixels were used for evaluation of the in vivo thickness as well as the cellular infiltration into membrane interspaces at day 3 after implantation 7 . Briefly, measurements of the membrane thickness within the total scans at 15 different sites were conducted using the "Annotations and Measurements"-tool of the NISElements 4.0 software. These values were used to calculate the mean thickness of the materials and the standard derivations.

For analyses of the cellular penetration the distance of every invaded cell from their respective membrane surface, i.e. the compact or the spongy part of the membrane, was also measured using the "Annotations and Measurements"-tool of the software in $\mu \mathrm{m}$. To compare the infiltration depth on both materials, the depth of the cells was related to materials thickness and their percent infiltration was determined.

\section{Statistical analysis}

The quantitative study data were examined by analyses of variance (ANOVA) followed by Least Significant Difference (LSD) post-hoc assessments to compare the groups using the PASW Statistics 18.0 software (SPSS Inc., Chicago, IL, USA).

Differences were considered significant if their $p$-values were less than $0.05(p<0.05)$. Finally, the GraphPad Prism 5.0d software (GraphPad Software Inc., La Jolla, CA, USA) was used for plotting graphs. Quantitative data were presented as the mean \pm standard deviation.

\section{RESULTS}

\section{Microscopical structural differences of the two materials in dry condition}

Although MG and BG are both native bilayered type I and III collagens, differences could already be observed when looking at their structure at low magnification. MG, the bilayered matrix, is markedly thicker and upholds a nearly three-fold volume when compared to BG (Figure 1, A1 and $B 1)$. MG is composed of a thin and rather compact layer and a thicker and spongy side. BG, on the other hand is a bilayered membrane, which finds expression by its thinner and malleable handling. This membrane is also composed of two layers, of which one layer appears smooth and compact, while the other layer appears spongy with wave/ cord-like structures.

The microscopic analyses of the present study at a higher magnification showed that MG (Figure 1, $A 2$ and $A 3$ ) and BG (Figure 1, B2 and B3) differed morphologically in their corresponding sides. Wavelike structures seem to be imprinted on the compact layer of BG, while the respective side of MG tends to be rather even. When comparing the spongy layers, cord-like structures were visible for BG, while the respective MG side appeared more homogeneous, with smaller and larger pores visible.

\section{Thickness of the two materials in dry and wet conditions}

The measurements revealed a high statistical difference of the thickness of the MG matrix $(1800 \pm 41.35 \mu \mathrm{m})$ compared to the BG membrane $(438.9 \pm 64.81 \mu \mathrm{m})$ in dry conditions $(p<0.001)$ (Figure 2). The humification of the collagen-based materials still revealed a high statistical difference between both materials (MG: 2,914.3 $\pm 50.27 \mu \mathrm{m}$, BG: $444.1 \pm 38.70 \mu \mathrm{m})(p<0.001)$. Unexpectedly, the thickness of the BG membrane did not significantly change after humification, while the thickness of the MG matrix varied significantly due to its $\mathrm{NaCl}$ dependent swelling when comparing 
the dry and wet conditions $(p<0.001)$ (Figure 2).

\section{In vitro results}

\section{Cell viability and proliferation pattern}

On the spongy sides of both matrix (MG) and membrane (BG), the cellular proliferation was initiated from small cell islands, which were established very early, followed by spreading over the entire membrane after 48 hours. On the compact sides of both materials, different growth patterns were observed (Figures 3, A and C). On the spongy side of BG (Figure $3 \mathrm{~B}$ ), cells tended to seed between the described cord-like structures using the grooves as a guide rail, where cellular proliferation became initiated. In contrast to this growth pattern, the cells on the spongy layer of the MG matrix (Figure 3D) seemed to be evenly distributed within the three-dimensional spongy layer.
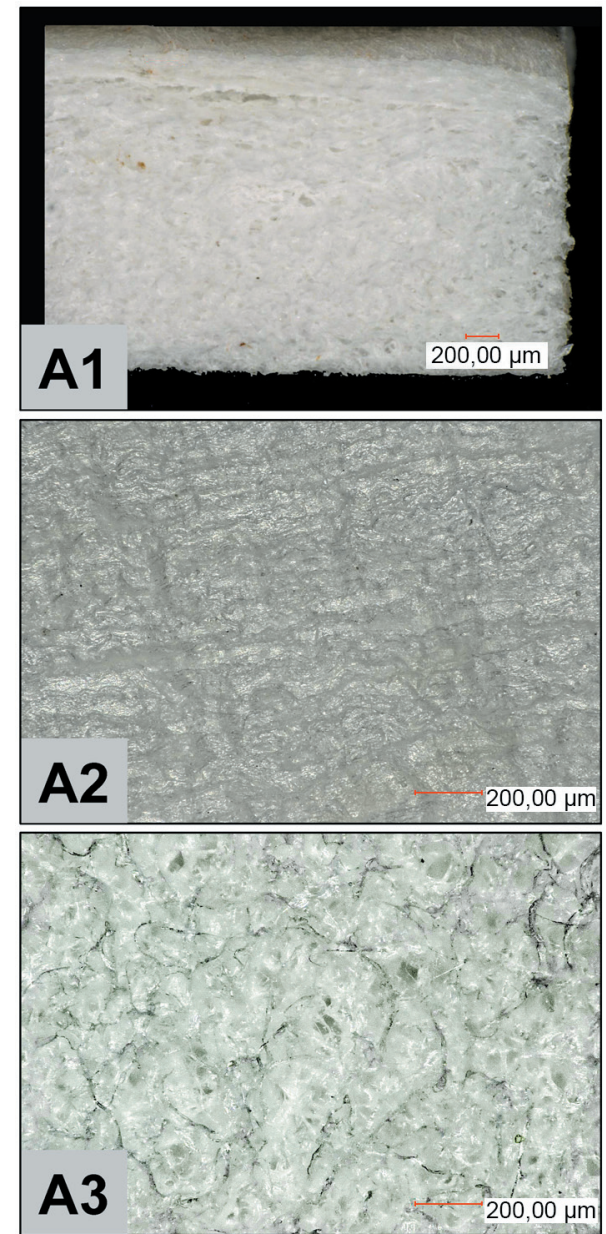

Comparative analysis of cell proliferation rates

The measurements revealed statistically significant differences between the various study groups for the human gingival fibroblast proliferation after 48 hours (Figure 4). Comparison of the proliferation of fibroblasts on the different sides of the two materials revealed a highly significant decrease between the activity on the spongy side of Mucograft compared to proliferation activity on both sides of the BioGide membrane ( $C L: p<0.01$; SL: $p<0.001$ ) (Figure 4). Furthermore, statistically significant differences regarding the fibroblast proliferation between the compact and the spongy side in case of both materials were measured (BioGide: $p<0.05$; Mucograft: $p<0.001$ ) (Figure 4).

\section{Histological and histomorphometrical results \\ Both collagen-based materials were prominently detectable within the surrounding tissue 3 days}
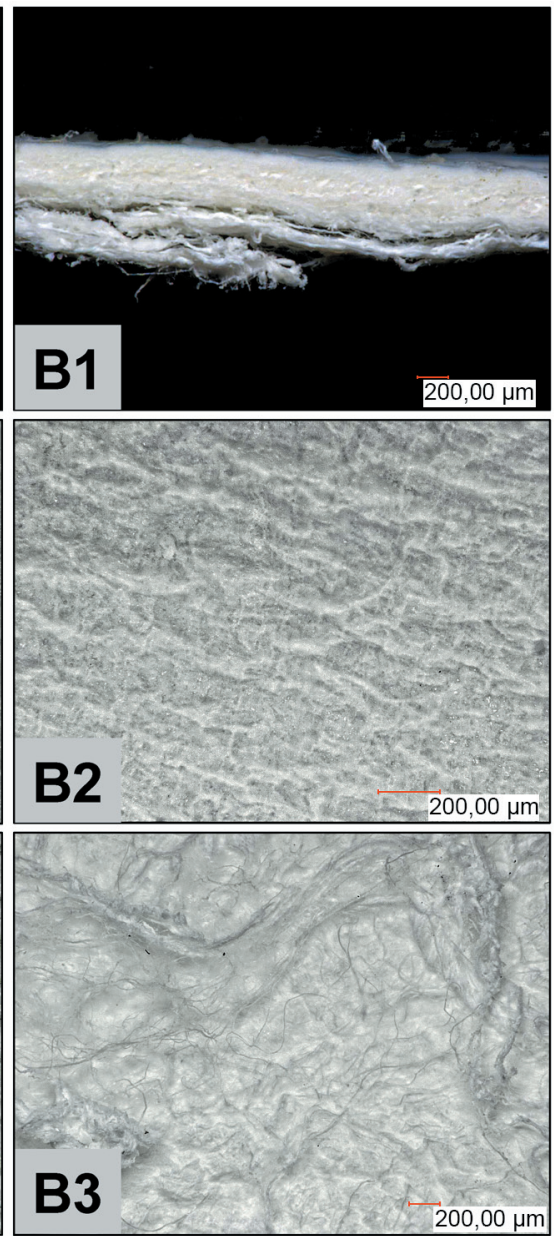

Figure 1- Macroscopic and microscopic structural characteristics of both collagen-based materials (MG and BG). A1 and $B 1$ show cross-sections of the analyzed materials $(A=M G)$ and $(B=B G), A 2$ and $B 2$ show the ultrastructure of the compact surface of $M G$ and $B G$ respectively, while $A 3$ and $B 3$ highlight the corresponding spongy side of the used materials. Magnifications: A1 and B1 x100; A2-3 and B2-3 x200 (scale bar=200 $\mu \mathrm{m}$ )

$M G=$ Mucograft

$B G=$ BioGide 
after implantation (Figure 5, A1 and B1; double arrows). Thereby, the two parts of the membranes, i.e. the spongy $(\mathrm{SL})$ and the compact layer $(\mathrm{CL})$ were differentiable. Only single cells penetrated the interspaces of both materials (Figure 5, A2-3 and B23). The histopathological evaluation revealed a mild mononuclear tissue reaction to the two investigated materials at day 3 after implantation. Using special histochemical and immunohistochemical staining methods, fibroblasts (blue arrows) as well as granulocytes (green arrows) were observed at this early study time point at the biomaterial-tissue-

\section{Comparative thickness}

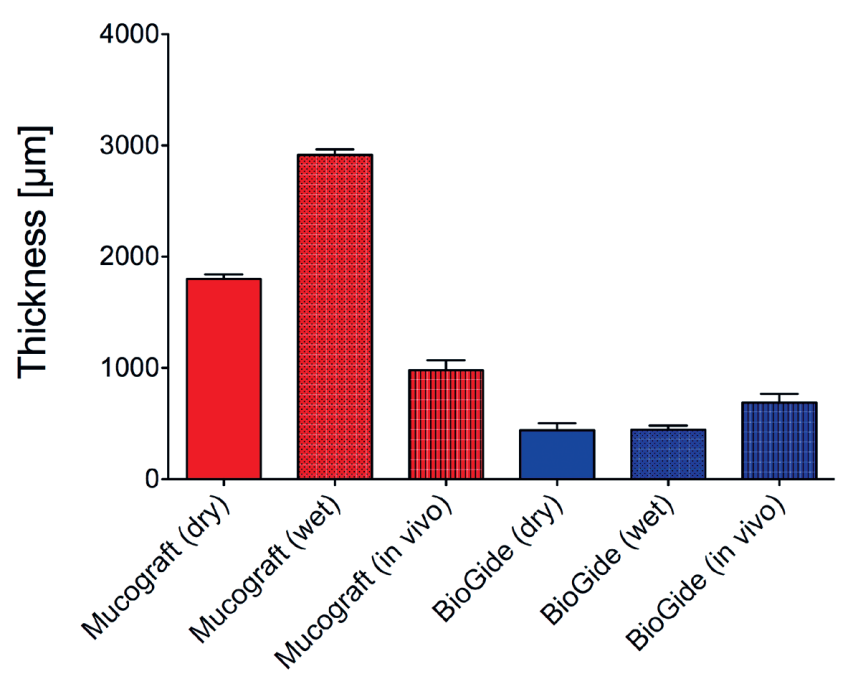

Figure 2- Comparative thickness measurement analyses of the membranes (dry, wet and in vivo)
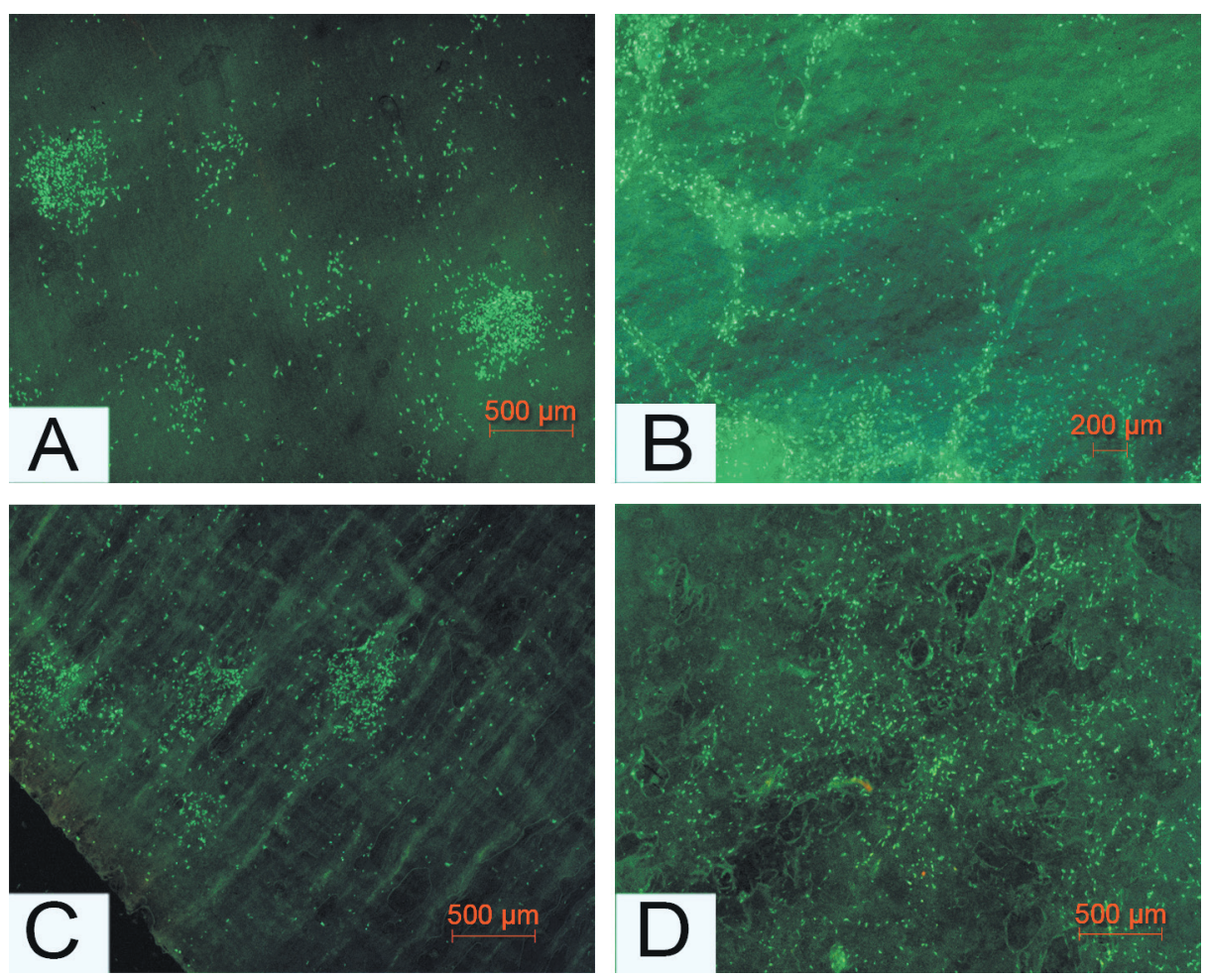

Figure 3- Growth behavior of human gingival fibroblasts on both sides of the two materials. A (BG) and C (MG) show the fluorescent visualization of distribution/growth behavior of the gingival fibroblast on the compact layers of the materials, while $B(B G)$ and $D(M G)$ display the cellular behavior on the spongy layers of the materials. Magnifications: $A$ and $C \times 200$;

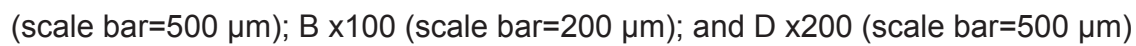




\section{Comparative proliferation of human gingival fibroblasts $(48 \mathrm{~h})$}

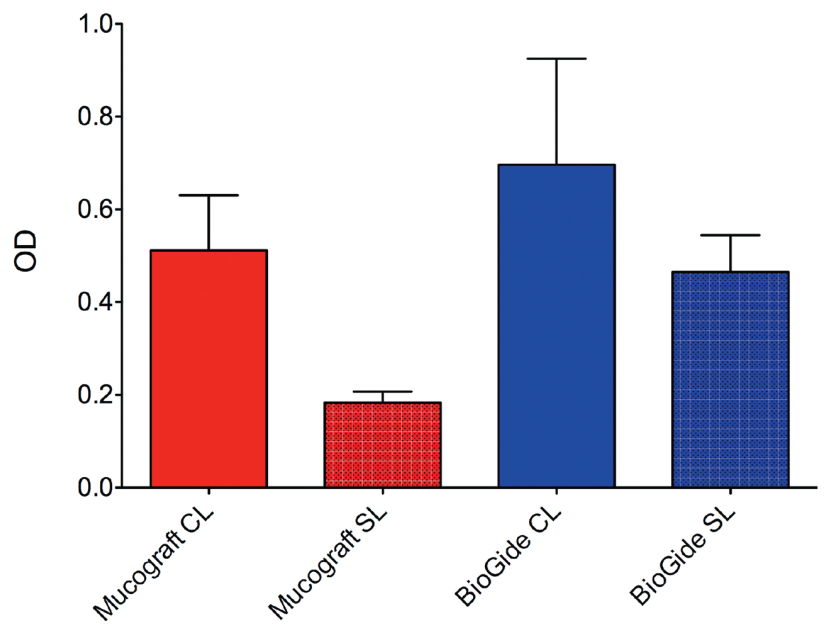

Figure 4- Results of the proliferation assay (WST-1 Test; means \pm SD) after 48 hours with human gingival fibroblasts related to the two sides ( $C L=$ compact layer, $S L=$ spongy layer) of Mucograft $(\mathrm{MC})$ or BioGide $(B G)$, and with cells without membranes (control groups MG and BG)
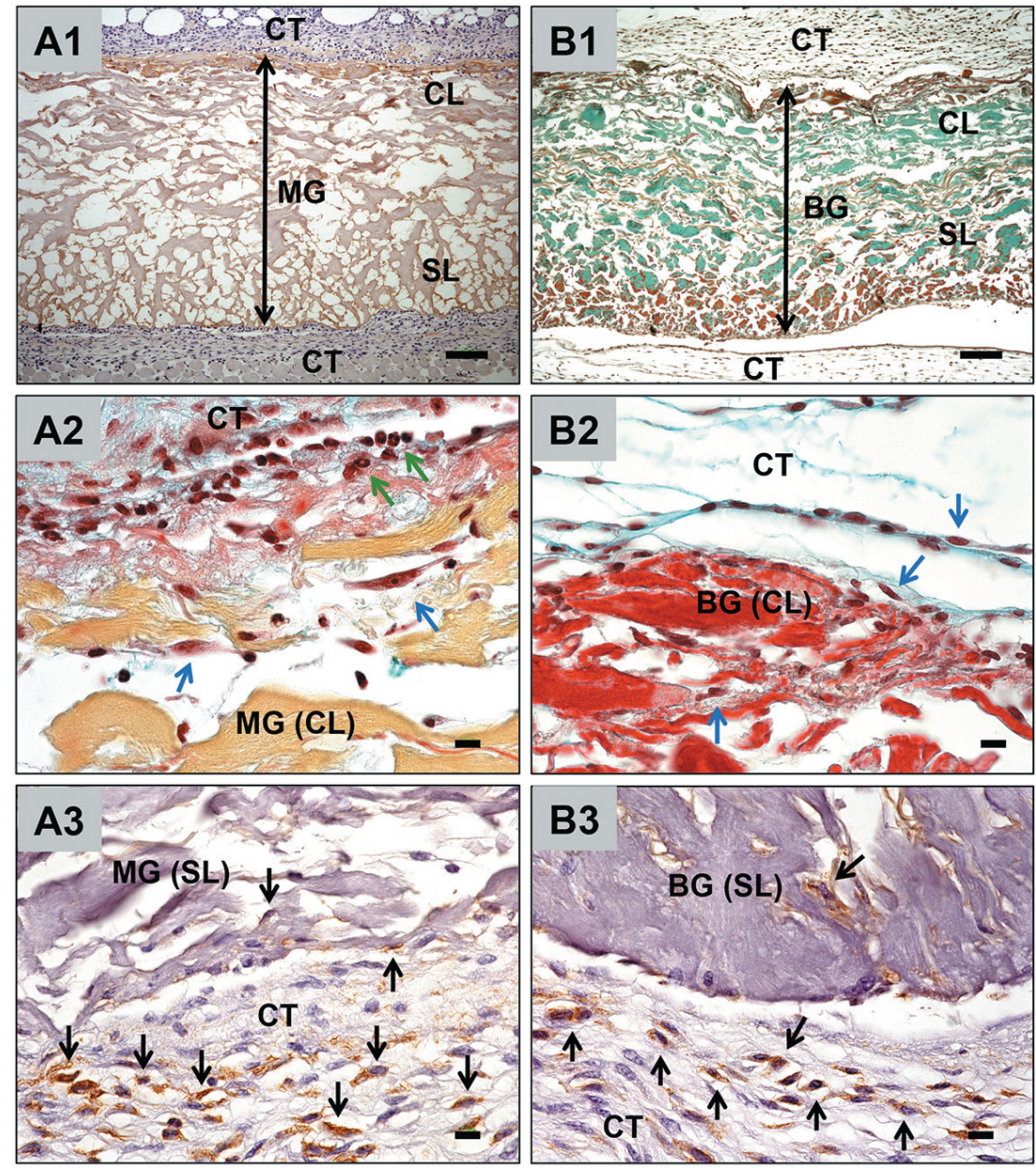

Figure 5- Cellular interactions with the materials within the subcutaneous connective tissue (CT) of CD-1 mice. A1-3 show the tissue reactions to the Mucograft (MG) matrix, B1-3 show the tissue reaction to the BioGide (BG) membrane. Magnifications: A1 and B1 x100; (scale bar=100 $\mu \mathrm{m}$ ); A2-3 and B2-3 x600; (scale bar=10 $\mu \mathrm{m}$ ). CL=compact layer, $\mathrm{SL}=$ spongy layer. Blue arrows indicate fibroblasts (A2, B2), green arrows indicate granulocytes (A2), black arrows indicate macrophages $(A 3, B 3)$ 
interface, as well as within the peri-implant tissue (Figure 5, A2-3 and B2-3). In addition, the periimplant tissue of both materials showed no signs of extensive inflammation or fibrosis at this early time point. The histomorphometric analysis of the in vivo thickness of both materials revealed a high statistical difference at day 3 after implantation between the Mucograft matrix (979.9 189.98 $\mu \mathrm{m})$ and the BioGide membrane (687.0 779.49 $\mu \mathrm{m})(p<0.001)$ (Figure 2). This implies that the Mucograft matrix in all conditions shows a high significant increased thickness compared to the thickness of all conditions of the BioGide membrane. Interestingly, a comparison of the different thickness values of Mucograft in the different conditions showed a high significant statistical difference of both in vitro conditions and the in vivo condition $(p<0.001)$, while no significant differences were measurable between the three conditions of the BioGide membrane (Figure 2).

The histomorphometric analysis of the cellular penetration depth revealed no statistical differences related to the both whole materials, i.e. both sides of the materials (MG: $6.38 \pm 4.66 \%$; BG: $7.35 \pm 5.82 \%$ ). The precise comparative analysis of the cellular penetration depth of the two different materials parts, i.e. the spongy layer (SL) and the compact layer (CL) showed no statistical differences.

\section{DISCUSSION}

In the present study, the cell and tissue reactions to two commercially available porcine-based noncross-linked collagen type I and III materials were investigated. Both $M G$ and $B G$ play an important part in GTR and GBR procedures ${ }^{23,25}$. These materials have been used for many different applications, e.g. to cover buccal gingival areas in Taiwanese dogs ${ }^{5}$ or vertical dehiscence bony defects after implantation in patients ${ }^{14}$, for healing of artificial bone defects and buccal recessions in male dogs ${ }^{22}$, to evaluate interproximal infrabony defects in patients ${ }^{11}$, and also to study the reduction of bone resorption in Labrador dogs after insertion of implants ${ }^{3}$.

The spongy side of BG is defined by cord-like structures, while the corresponding side of MG has a rather plane structure with multiple pores being visible. In this study, the cellular growth patterns of human fibroblasts were analyzed on both sides of the materials. Interestingly, the cells on the two spongy sides of MG and BG significantly differed in their growth pattern. While on the spongy side of BG the cells grew alongside the cord-like structures, a more homogeneous distribution of cells was observed on the corresponding side of MG. This different cell proliferation pattern on both materials should relate to their clinical application. In this study, cell proliferation rates were investigated by means of a WST- 1 assay. The data of the comparative analysis of cell proliferation rates show that, in comparison to the spongy layers, the compact layers of both materials allowed, at an observation time of 48 h, a markedly higher cellular proliferation.

The spongy surface structure on the BG membrane and the multiple pores on the respective MG side obviously account for the lower proliferation rates. Interestingly, cell proliferation on both BG surfaces was higher when compared to that of the spongy surface of MG. Several in vitro investigations have been performed which mainly focus on how different collagen barrier membranes influence cellular proliferation on selected cell lines like HUVECs (human umbilical vein endothelial cells), MG63s (human osteosarcoma cell lines), human mononuclear calls and PDLs (periodontal ligament fibroblasts) or hMSCs (human mesenchymal stem cells), respectively.

Mononuclear cells were incubated with collagen membranes of porcine or bovine origin up to 48 hours, and, subsequently, the cytotoxic potential of the membranes was evaluated using the MTT assay ${ }^{17}$. It was shown that all collagen membranes, and in particular those of porcine origin, caused an increased production of pro-inflammatory mediators in the mononuclear cells and a decreased cellular proliferation. These findings contradict the results from a study ${ }^{15}$, where the proliferation of hMSCs incubated with collagen membranes was studied, using the lactate dehydrogenase and MTT assays. After 4 days of incubation, the porcinebased collagen membranes showed low levels of cytotoxicity, and significantly enhanced cellular proliferation in comparison to the controls.

It has been shown that non-cross-linked collagen type I and type III membranes like BG can trigger cellular proliferation ${ }^{21,23,24}$. These data are also in accordance with the results from the present study, were an enhanced proliferation of human gingival fibroblasts was observed.

Prewashing of the membranes has been recommended to further enhance cellular proliferation ${ }^{12}$. Both materials used in this study showed good cell viability on both of their surfaces without further prewashing.

In addition to the analyses of the in vitro cell reaction to the materials, the present study assessed the tissue reaction of the CD-1 mouse to the two collagen-based materials by histological and histomorphometrical analysis. The in vivo data showed that after implantation both materials underwent an early integration into the surrounding tissue. Thereby, eosinophils and fibroblasts were involved in the tissue reaction to both materials.

This study analyzed the cell penetration depth 
into the materials on a histomorphometrical basis. The results show that, although BG and MG differ in their thickness, the percentages of the cells, which penetrated into the materials, were comparable. Considering the present in vitro data, it becomes obvious that fibroblasts proliferate well on both layers of both materials. The findings of this combined in vitro and in vivo study show that the two investigated materials are cell and tissue compatible, serving as reliable barriers, with their respective indication for GTR (MG) and GBR (MG, BG) techniques.

Regarding these observations, one has to take into consideration that studies employing animal models can only be applied to human tissue reactions with certain limitations, and that different types of healing processes are characteristic for particular animals.

In a clinical study ${ }^{20}$, bone defects in mongrel dogs were treated with $\mathrm{GBR}, \mathrm{BG}$ and the combination of GBR and BG. After an observation time of 5 months, all materials lead to a bone fill, but there was no statistically significant difference between the different treatments. In contrast, in a study with beagle dogs ${ }^{10}$, no improvement in the clinical parameters could be detected three months after treatment with GTR. Different results were obtained, either when GTR was employed in the tibiae of adult New Zealand rabbits ${ }^{4}$ or when also using the GTR technique, but in the hound dog model $^{1}$. In both studies, significant amounts of bone regeneration were found after six (rabbit) or 18 weeks (hound dog) of observation.

Taking the results of this combined in vitro and in vivo study into consideration, clinical studies now have to confirm MGs potential to be successfully applied in oral soft tissue regeneration.

\section{CONCLUSION}

The present study analyzed the suitability of two collagen materials, a matrix vs. a membrane for application in guided tissue and bone regeneration, via in vitro and in vivo analyses. In vivo, MG showed a three-fold higher thickness both in dry and wet conditions, when compared to BG. In vitro, fibroblasts were more inclined to proliferate on the compact layers of both collagens with the highest values on the compact side of BG. In vivo, at day three after implantation both materials underwent good integration into the surrounding tissue both not allowing any cell ingrowth on the compact side, but MG porous side serving as a scaffold for fibroblasts. The results of the present study underline that both collagens are already at this early stage of tissue integration suitable materials, while having cell proliferative and correspondingly non-toxic surfaces. Further clinical studies are necessary to support these experimental data.

\section{ACKNOWLEDGMENT}

The authors would like to thank Mrs. Claudia Darmstadt and Mrs. Ulrike Hilbig for their excellent technical assistance.

\section{CONFLICT OF INTEREST AND SOURCE OF FUNDING STATEMENT}

The authors declare that they have no conflict of interest. Part of the materials was provided by Geistlich Pharma AG, Wolhusen, Switzerland.

\section{REFERENCES}

1- Becker W, Becker BE, Handelsman M, Ochsenbein C, Albrektsson T. Guided tissue regeneration for implants placed into extraction sockets: a study in dogs. J Periodontol. 1991;62:703-9.

2- Bunyaratavej P, Wang HL. Collagen membranes: a review. J Periodontol. 2001;72:215-29.

3- Caneva M, Botticelli D, Salata LA, Scombatti Souza SL, Carvalho Cardoso L, Lang NP. Collagen membranes at immediate implants: a histomorphometric study in dogs. Clin Oral Imp Res. 2010;21:891-7.

4- Dahlin C, Sennerby L, Lekholm U, Linde A, Nyman S. Generation of new bone around titanium implants using a membrane technique: an experimental study in rabbits. Int J Oral Maxillofac Implants. 1989;4:19-25.

5- Dung SZ, Tu YK, Lu HK. Soft tissue response to fenestration type defects in the gingiva treated with various barrier membranes for regeneration. J Dent Sci. 2013. Epub ahead of print. Available from: http://dx.doi.org/10.1016/j.jds.2013.02.021.

6- Eickholz P, Pretzl B, Holle R, Kim TS. Long-term results of guided tissue regeneration therapy with non-resorbable and bioabsorbable barriers. III. Class II furcations after 10 years. J Periodontol. 2006;77:88-94.

7- Ghanaati S. Non-cross-linked porcine-based collagen I-III membranes do not require high vascularization rates for their integration within the implantation bed: a paradigm shift. Acta Biomater. 2012;8:3061-72.

8- Ghanaati S, Schlee M, Webber MJ, Willershausen I, Barbeck M, Balic $E$, et al. Evaluation of the tissue reaction to a new bilayered collagen matrix in vivo and its translation to the clinic. Biomed Mater. 2011;6:015010.

9- Greenstein G, Caton JG. Biodegradable barriers and guided tissue regeneration. Periodontol 2000. 1993;1:36-45.

10- Grunder U, Hürzeler MB, Schüpbach P, Strub JR. Treatment of ligature-induced peri-implantitis using guided tissue regeneration: a clinical and histological study in the beagle dog. Int J Oral Maxillofac Implants. 1993;8:282-93.

11- Guimarães MC, Passanezi E, Sant'Ana AC, Greghi SL, Taba Junior M. Digital subtraction radiographic analysis of the combination of bioabsorbable membrane and bovine morphogenetic protein pool in human periodontal infrabony defects. J Appl Oral Sci. 2010;18(4):379-84.

12- Kim TS, Holle R, Hausmann E, Eickholz P. Long-term results of guided tissue regeneration therapy with non-resorbable and bioabsorbable barriers. II. A case series of infrabony defects. J Periodontol. 2002;73:450-9.

13- Lang NP, Hämmerle $\mathrm{CH}$, Brägger $U$, Lehmann B, Nyman SR. Guided tissue regeneration in jawbone defects prior to implant placement. Clin Oral Implants Res. 1994;5(2):92-7.

14- Lee JY, Lee J, Kim YK. Comparative analysis of guided bone regeneration using autogenous tooth bone graft material with and without resorbable membrane. J Dent Sci. 2013;8:281-6. 
15- Liu Q, Humpe A, Kletsas D, Warnke F, Becker ST, Douglas T, et al. Proliferation assessment of primary human mesenchymal stem cells on collagen membranes for guided bone regeneration. Int J Oral Maxillofac Implants. 2011;26:1004-10.

16- McGuire MK, Scheyer ET. Xenogeneic collagen matrix with coronally advanced flap compared to connective tissue with coronally advanced flap for the treatment of dehiscence-type recession defects. J Periodontol. 2010;81:1108-17.

17- Moura CC, Soares PB, Carneiro KF, Souza MA, Magalhães

$D$. Cytotoxicity of bovine and porcine collagen membranes in mononuclear cells. Braz Dent J. 2012;23(1):39-44.

18- Needleman I, Tucker R, Giedrys-Leeper E, Worthington H. A systematic review of guided tissue regeneration for periodontal infrabony defects. J Periodontal Res. 2002;37:380-8.

19- Needleman IG, Worthington HV, Giedrys-Leeper E, Tucker RJ. Guided tissue regeneration for periodontal infra-bony defects. Cochrane Database Syst Rev. 2006;(2):CD001724.

20- Nociti Júnior FH, Caffesse RG, Sallum EA, Machado MAN, Stefani CM, Sallum AW. Clinical study of guided bone regeneration and/or bone grafts in the treatment of ligature-induced periimplantitis defect in dogs. Braz Dent J. 2001;12(2):127-31.

21- Papaioannou KA, Markopoulou CE, Gioni V, Mamalis AA, Vayouraki HN, Kletsas D, et al. Attachment and proliferation of human osteoblast-like cells on guided bone regeneration (GBR) membranes in the absence or presence of nicotine: an in vitro study. Int J Oral Maxillofac Implants. 2011;26:509-19.
22- Rosetti EP, Marcantonio RA, Cirelli JA, Zuza EP, Marcantonio $E$ Jr. Treatment of gingival recession with collagen membrane and DFDBA: a histometric study in dogs. Braz Oral Res. $2009 ; 23(3): 307-12$.

23- Rothamel D, Schwarz F, Sager M, Herten M, Sculean A, Becker J. Biodegradation of differently cross-linked collagen membranes: an experimental study in the rat. Clin Oral Implants Res. 2005;16:369-78.

24- Rothamel D, Schwarz F, Sculean A, Herten M, Scherbaum W, Becker J. Biocompatibility of various collagen membranes in cultures of human PDL fibroblasts and human osteoblast-like cells. Clin Oral Implants Res. 2004;15:443-9.

25- Sanz M, Lorenzo R, Aranda JJ, Martin C, Orsini M. Clinical evaluation of a new collagen matrix (Mucograft prototype) to enhance the width of keratinized tissue in patients with fixed prosthetic restorations: a randomized prospective clinical trial. J Clin Periodontol. 2009;36:868-76.

26- Sculean A, Nikolidakis D, Schwarz F. Regeneration of periodontal tissues: combinations of barrier membranes and grafting materials - biological foundation and preclinical evidence: a systematic review. J Clin Periodontol. 2008;35:106-16.

27- Weigel C, Brägger U, Hammerle $\mathrm{CH}$, Mombelli A, Lang NP. Maintenance of new attachment 1 and 4 years following guided tissue regeneration (GTR). J Clin Periodontol. 1995;22:661-9. 